\title{
Non-invasive ventilation in acute exacerbations of chronic obstructive pulmonary disease: long term survival and predictors of in-hospital outcome
}

\author{
P K Plant, J L Owen, M W Elliott
}

\begin{abstract}
Background-Non-invasive ventilation (NIV) reduces the need for intubation and the mortality associated with an exacerbation of chronic obstructive pulmonary disease (COPD). This study aimed to identify factors that could be used to stratify patients according to their risk of requiring invasive mechanical ventilation. The second aim was to determine the long term survival of patients treated with and without NIV.

Methods-In this prospective multicentre randomised controlled trial 118 patients were allocated to standard treatment and 118 to NIV between November 1996 and September 1998. Arterial blood gas tensions and respiratory rate were recorded at enrolment and after 1 and 4 hours. Prognostic factors were identified using logistic regression analysis. All patients were fol-
\end{abstract} lowed until death or 1 January 1999.

Results-At enrolment the $\mathbf{H}^{+}$concentration (OR 1.22 per nmol/1, 95\% CI 1.09 to $1.37, \mathrm{p}<0.01)$ and $\mathrm{PaCO}_{2}(\mathrm{OR} 1.14$ per $\mathrm{kPa}$, $95 \% \mathrm{CI} 1.14$ to $1.81, \mathrm{p}<0.01$ ) were associated with treatment failure. Allocation to NIV was protective (OR $0.39,95 \%$ CI 0.19 to 0.80 ). After 4 hours of treatment improvement in acidosis (OR 0.89 per nmol/1, 95\% CI 0.82 to $0.97, p<0.01$ ) and fall in respiratory rate (OR 0.92 per breaths $/ \mathrm{min}, 95 \% \mathrm{CI} 0.84$ to $0.99, \mathrm{p}=0.04$ ) were associated with success. Median length of survival was $\mathbf{1 6 . 8}$ months in those treated with NIV and $\mathbf{1 3 . 4}$ months in those receiving standard treatment $(p=0.12)$. The trend in improved survival was attributable to prevention of death during the index admission.

Conclusion-Initial pH and hypercapnia can be used to stratify groups of patients according to their risk of needing intubation. NIV reduces this risk and progress should be monitored using change in respiratory rate and $\mathrm{pH}$. The long term survival after NIV is sufficiently good to render treatment appropriate.

(Thorax 2001;56:708-712)

Keywords: non-invasive ventilation; chronic obstructive pulmonary disease; long term survival

Non-invasive ventilation (NIV) has been shown in randomised controlled trials to improve arterial blood gas tensions and dyspnoea and to prevent the need for intubation in patients admitted to hospital with an exacerbation of chronic obstructive pulmonary disease (COPD) associated with decompensated respiratory acidosis. ${ }^{1-7}$ In the two largest trials in-hospital mortality was also reduced. Brochard et al, in the ICU environment, reduced the need for intubation from $74 \%$ to $25 \%$ and mortality from $29 \%$ to $9 \% .{ }^{1}$ In a 14 centre randomised controlled trial we have shown that NIV used early in the admission in the ward environment was, firstly, feasible but also reduced the need for intubation using a priori criteria from $27 \%$ to $15 \%$, real intubation rates from $10 \%$ to $6 \%$, and in-hospital mortality from $20 \%$ to $10 \%{ }^{7}$

If ward based NIV is to be widely adopted into clinical practice, it would be useful to identify individuals who are likely to fail to respond to NIV either before or shortly after a trial of therapy. This will allow such patients to be managed in a higher dependency area or an ICU with ready access to invasive mechanical ventilation. The failure to do this may lead to a delay in intubation and an increase in mortality. ${ }^{8}$

It is also possible that the subgroup in which death is avoided is a high risk group who will die shortly after discharge in association with another exacerbation. If this occurs, the appropriateness of offering NIV in the first place may need to be questioned. This paper reports the long term survival of patients recruited into the randomised controlled trial and explores the data set for factors associated with treatment failure during the hospital admission.

\section{Methods}

CLINICAL TRIAL

The methods for this 14 centre randomised controlled trial have been described previously. ${ }^{7}$ Between November 1996 and September 1998, 236 patients admitted to hospital with an acute exacerbation of COPD with a respiratory rate $>23 / \mathrm{min}$ and a mild to moderate respiratory acidosis $\left(\mathrm{pH} 7.25-7.35, \mathrm{PaCO}_{2}\right.$ $>6 \mathrm{kPa}$ ) were randomised to receive standard treatment with $(n=118)$ or without $(n=118)$ the addition of bi-level NIV. Arterial blood gas tensions and respiratory rate were measured at enrolment and 1 and 4 hours after randomisation. The primary end point was "need for intubation". This was defined using a set of objective criteria, avoiding the inconsistencies associated with intubation on clinical grounds. Patient were considered to have "needed intubation" if they met any of the following criteria within 14 days of admission: (a) $\mathrm{pH}<7.20$, (b) $\mathrm{pH} 7.20-7.25$ on two occasions 1 hour apart, 
Table 1 Characteristics of patients with acute exacerbations of chronic obstructive pulmonary disease assigned to standard treatment or non-invasive ventilation

\begin{tabular}{lll}
\hline Characteristic & Standard treatment $(n=118)$ & NIV $(n=118)$ \\
\hline Mean (SD) age (years) & $69(8)$ & $69(7)$ \\
$\mathrm{M}: \mathrm{F}$ & $63: 55$ & $54: 64$ \\
Respiratory rate (breaths/min) & $28(24-40)$ & $28(24-36)$ \\
$\mathrm{pH}^{\star}$ & $7.31(7.26-7.35)$ & $7.32(7.25-7.35)$ \\
$\mathrm{Mean}(\mathrm{SD}) \mathrm{PaCO}_{2}(\mathrm{kPa})$ & $8.65(1.70)$ & $8.82(1.51)$ \\
$\mathrm{PaO}_{2}(\mathrm{kPa})^{\star}$ & $7.00(4.71-12.31)$ & $6.88(4.50-13.8)$ \\
$\mathrm{FEV}_{1}$ at discharge $(\mathrm{l})^{\star}$ & $0.68(0.37-2.00)$ & $0.71(0.28-1.47)$ \\
\hline
\end{tabular}

$\mathrm{PaCO}_{2}, \mathrm{PaO}_{2}=$ arterial carbon dioxide and oxygen tensions; $\mathrm{FEV}_{1}=$ forced expiratory volume in one second.

${ }^{\star}$ Median data with 5 th and 95 th centiles.

Table 2 Variables at enrolment associated with failure of treatment

\begin{tabular}{llll}
\hline & $\begin{array}{l}\text { Univariate } \\
\text { analysis } \\
\text { V value }\end{array}$ & Multivariate analysis & \\
& 0.569 & & Odds ratio \\
Age & 0.526 & & \\
$\mathrm{Sex}$ & $<0.001$ & $1.22(1.09$ to 1.37$)$ per $\mathrm{nmol} / 1$ & $<0.01$ \\
$\mathrm{H}^{+}$ & 0.035 & & \\
$\mathrm{PaO}_{2}$ & $<0.001$ & $1.14(1.14$ to 1.81$) \mathrm{per} \mathrm{kPa}$ & $<0.01$ \\
$\mathrm{PaCO}_{2}$ & 0.330 & & \\
Respiratory rate $_{\text {Radiographic consolidation }}$ & 0.136 & $0.39(0.19$ to 0.80$)$ & $<0.01$ \\
Allocation to NIV & 0.038 & 0.39 &
\end{tabular}

$\mathrm{PaCO}_{2}, \mathrm{PaO}_{2}=$ arterial carbon dioxide and oxygen tensions; $\mathrm{NIV}=$ non-invasive ventilation.

Table 3 Relative risk of failure judged at enrolment compared with a patient with a pH of 7.35 and $\mathrm{PaCO}_{2} 6 \mathrm{kPa}$ treated without NIV

\begin{tabular}{llllll}
\hline \multirow{2}{*}{$p H$} & \multicolumn{2}{c}{$\mathrm{PaCO}_{2}$} & & \\
\cline { 3 - 6 } & Treatment & $6 \mathrm{kPa}$ & $8 \mathrm{kPa}$ & $10 \mathrm{kPa}$ & $12 \mathrm{kPa}$ \\
\hline \multirow{2}{*}{7.35} & Standard & 1.00 & 1.30 & 1.69 & 2.19 \\
7.30 & + NIV & 0.39 & 0.51 & 0.66 & 0.86 \\
& Standard & 2.96 & 3.84 & 5.00 & 6.49 \\
7.25 & + NIV & 1.15 & 1.50 & 1.95 & 2.53 \\
& Standard & 9.98 & 12.97 & 16.85 & 21.90 \\
& + NIV & 3.89 & 5.06 & 6.57 & 8.54 \\
\hline
\end{tabular}

(c) hypercapnic coma (Glasgow coma scale $<8$ and $\mathrm{PaCO}_{2}>8 \mathrm{kPa}$ ), (d) $\mathrm{PaO}_{2}<6 \mathrm{kPa}$ despite maximum tolerated $\mathrm{FiO}_{2}$, and (e) cardiorespiratory arrest. Secondary end points included in-hospital mortality.

ANALYSIS OF FACTORS ASSOCIATED WITH FAILURE The identification of factors associated with failure was carried out using three analytical steps. Univariate analysis was performed between subjects who were managed successfully and those who met the a priori failure criteria. Continuous variables were compared with unpaired $t$ tests for parametric data and the Mann-Whitney U test for non-parametric data. Categorical data were compared using Fisher's exact test. All tests and $p$ values were two tailed and analysed on an intention to treat basis. Variables with $\mathrm{p}$ values $<0.10$ were then entered into a forward stepwise logistic regression analysis. Variables with a $\mathrm{p}$ value $<0.05$ were considered statistically significant and are reported as odds ratios (OR) with 95\% confidence intervals (CI). Finally, the ability of the derived regression equation to identify those who failed in the trial was considered. Sensitivity, specificity, positive and negative predictive values are reported.

The analysis was firstly performed for variables available at enrolment to try to identify those who will fail before NIV is commenced; these variables were age, sex, $\mathrm{pH}$, $\mathrm{PaCO}_{2}, \mathrm{PaO}_{2}$, respiratory rate, consolidation on chest radiograph, and the decision to offer NIV. $\mathrm{pH}$ was converted to $\mathrm{H}^{+}$concentration in all analyses. A second analysis was made using variables available 4 hours after randomisation. These included the variables above plus absolute values of $\mathrm{H}^{+}$concentration, $\mathrm{PaCO}_{2}$, $\mathrm{PaO}_{2}$, and respiratory rate at 1 and 4 hours as well as change in $\mathrm{H}^{+}$concentration, $\mathrm{PaCO}_{2}$, $\mathrm{PaO}_{2}$, and respiratory rate between randomisation and 1 and 4 hours. Analyses were performed using version 7 of the SPSS statistical software package.

LONG TERM SURVIVAL

The survival of the two cohorts of patients was assessed to 1 January 1999 (minimum follow up 3 months, maximum 26 months) by writing and telephoning the patients' general practitioners (GPs). Where GPs were unknown or the patient had subsequently changed their GP, the hospital computerised patient administration systems (PAS) were searched. To allow for data entry onto the hospital PAS, the systems were searched 6 months after the census date. Survival was taken from enrolment in the study and not from the point of discharge. KaplanMeier curves were generated for survival data and compared using the log rank test.

\section{Results}

CLINICAL TRIAL

One hundred and eighteen patients were allocated to standard treatment and 118 to NIV. The characteristics of both groups were similar (table 1). Thirty two of the 118 patients $(27.1 \%)$ in the standard treatment group met the primary end point "need for intubation" compared with 18 of the $118(15.3 \%)$ in the NIV group $(\mathrm{p}<0.02)$. In-hospital mortality was also reduced: $24 / 118(20.3 \%)$ of the standard group died compared with $12 / 118$ in the NIV group $(10.2 \%)(\mathrm{p}=0.046){ }^{7}$

\section{FACTORS ASSOCIATED WITH THE FAILURE OF TREATMENT}

At enrolment only three variables were associated with subsequent failure of treatment on univariate analysis (table 2): severity of acidosis $(p<0.001)$, degree of hypercapnia $(p<0.001)$, and severity of hypoxia $(p=0.035)$. Allocation to NIV was protective $(\mathrm{p}=0.038)$. On multivariate analysis only three variables remained: $\mathrm{H}^{+}$concentration (OR 1.22 per nmol/1, 95\% CI 1.09 to $1.37, \mathrm{p}<0.01), \mathrm{PaCO}_{2}$ (OR 1.14 per $\mathrm{kPa}$, $95 \%$ CI 1.14 to $1.81, \mathrm{p}<0.01$ ), and allocation to NIV (OR 0.39, 95\% CI 0.19 to 0.80 , $\mathrm{p}<0.01)$. However, this model had poor discriminant value, only predicting $82 \%$ of the outcomes correctly with a sensitivity of $22 \%$ and a specificity of $97 \%$. The predictive value of failure was $67 \%$ and of success was $83 \%$. Despite this, these three variables are useful for stratifying patients according to risk (table 3). Compared with a patient with a $\mathrm{pH}$ of 7.35 and a $\mathrm{PaCO}_{2}$ of $6 \mathrm{kPa}$, a patient with a $\mathrm{pH}$ of 7.25 and a $\mathrm{PaCO}_{2}$ of $12 \mathrm{kPa}$ has a 22 -fold higher risk of meeting criteria for intubation. It can also be seen that the degree of acidosis is a greater risk factor clinically than the extent of hypercapnia. 
Table 4 Variables at 4 hours associated with failure of treatment

\begin{tabular}{|c|c|c|c|}
\hline \multirow[b]{2}{*}{ Variable } & \multirow{2}{*}{$\begin{array}{l}\text { Univariate } \\
\text { analysis } \\
\text { p value }\end{array}$} & \multicolumn{2}{|l|}{ Multivariate analysis } \\
\hline & & Odds ratio & p value \\
\hline \multicolumn{4}{|l|}{ At enrolment } \\
\hline $\mathrm{H}^{+}$ & $<0.001$ & $1.23(1.05$ to 1.43$)$ per $n m o l / 1$ & $<0.01$ \\
\hline $\mathrm{PaO}_{2}$ & 0.035 & & \\
\hline $\mathrm{PaCO}_{2}$ & $<0.001$ & 1.77 (1.28 to 2.45$)$ per $\mathrm{kPa}$ & $<0.01$ \\
\hline Allocation to NIV & 0.038 & & \\
\hline \multicolumn{4}{|l|}{ At 1 hour } \\
\hline Fall in $\mathrm{H}^{+}$ & 0.119 & & \\
\hline Change in $\mathrm{PaO}_{2}$ & 0.193 & & \\
\hline Change in $\mathrm{PaCO}_{2}$ & 0.276 & & \\
\hline Change in respiratory rate & 0.209 & & \\
\hline \multicolumn{4}{|l|}{ At 4 hours } \\
\hline Fall in $\mathrm{H}^{+}$ & 0.035 & $0.89(0.82$ to 0.97$)$ per $n m o l / 1$ & $<0.01$ \\
\hline Change in $\mathrm{PaO}_{2}$ & 0.896 & & \\
\hline Change in $\mathrm{PaCO}_{2}$ & 0.104 & & \\
\hline Change in respiratory rate & 0.009 & $0.92(0.84$ to 0.99$)$ per breath $/ \mathrm{min}$ & 0.04 \\
\hline
\end{tabular}

$\mathrm{PaCO}_{2}, \mathrm{PaO}_{2}=$ arterial carbon dioxide and oxygen tensions; $\mathrm{NIV}=$ non-invasive ventilation.

After 4 hours of treatment two additional variables were associated with treatment success on univariate analysis (table 4 ): fall in respiratory rate $(p=0.009)$ and an improvement in $\mathrm{H}^{+}$concentration $(\mathrm{p}=0.035)$. All six univariate variables were entered into the multivariate analysis of which four remained. At 4 hours the factors associated with a worse outcome were severity of acidosis (OR 1.23 per nmol/1, 95\% CI 1.05 to $1.43, \mathrm{p}<0.01)$ and hypercapnia (OR 1.77 per $\mathrm{kPa}, 95 \%$ CI 1.28 to $2.45, \mathrm{p}<0.01$ ) at enrolment. Fall in respiratory rate between admission and 4 hours was associated with success (OR 0.92 per breaths/min, 95\% CI 0.84 to $0.99, \mathrm{p}=0.04$ ) as was fall in $\mathrm{H}^{+}$ion concentration over the same time period (OR 0.89 per $\mathrm{nmol} / 1,95 \%$ CI 0.82 to $0.97, \mathrm{p}<0.01$ ). Allocation to NIV was no longer a statistically significant variable. However, this model also lacked discriminant ability, only predicting $85 \%$ of the outcomes correctly with a sensitivity of $30 \%$ and a specificity of $97 \%$. The predictive value of failure was $69 \%$ and of success was $87 \%$.

Despite this, the changes in $\mathrm{H}^{+}$concentration and respiratory rate can be used to assess risk in a clinically meaningful fashion (table 5). An improvement in $\mathrm{pH}$ over the first 4 hours from 7.30 to 7.35 is associated with a $47 \%$ reduction in the risk of failure. Similarly, a fall in respiratory rate of 8 breaths/min is associated with a $49 \%$ reduction in risk.

LONG TERM SURVIVAL

Follow up was achieved for all 236 patients to either death or 1 January 1999 . The median survival for all patients enrolled into the study was 15.9 months (95\% CI 12.6 to 19.2 ) with $58.4 \%$ surviving at 1 year. There was a trend to improved survival in the group receiving NIV

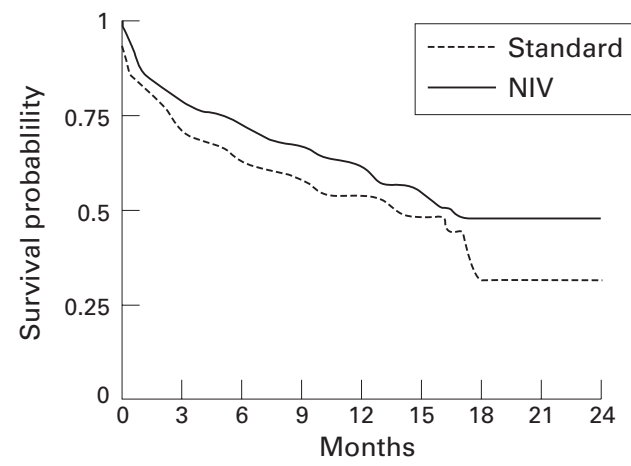

Figure 1 Kaplan-Meier plot of survival from enrolment. Median survival 13.4 months in standard treatment group $v 16.8$ months in NIV group $(p=0.12)$.

(fig 1). The 1 year survival in the NIV group was $61.6 \%$ compared with $53.9 \%$ in the standard treatment group. The median survival rates were 16.8 and 13.4 months, respectively. However, these differences were not statistically significant $(p=0.12)$. The curves suggest that the decline in survival was parallel after the first 3 months. Indeed, at 1 year $78.2 \%$ of the NIV patients who were alive at 3 months remained alive, which is very similar to the $75.7 \%$ of the standard treatment group.

\section{Discussion}

This study shows that the long term survival after NIV for acute exacerbations of COPD is worthwhile and identifies factors which can be used to monitor patients during the in-hospital period. Factors associated with long term survival were not analysed because of the lack of control during the follow up period and the paucity of data on co-morbidity.

LONG TERM SURVIVAL

The patients enrolled in the randomised controlled trial had a 1 year survival of $58 \%$. This is comparable to other long term studies of patients with COPD admitted with respiratory failure where 1 year survival has ranged from $57 \%$ to $88 \%$ in series where only a proportion of patients required ventilatory support, ${ }^{9-11}$ and from $34 \%$ to $56 \%$ in series where all patients receive ventilatory support. ${ }^{12-16}$ This suggests that our survival rates are typical. However, it is difficult to make accurate comparisons between these studies because of variations in study population (especially co-morbidity), the interventions received during the exacerbation (for example, invasive mechanical ventilation), and subsequent outpatient care.

There was a non-significant trend to improved survival in the NIV group compared with the standard treatment group with 1 year

Table 5 Relative risk of failure at 4 hours compared with admission

\begin{tabular}{lllllll}
\hline Initial $p H$ & pH at $4 h$ & $R R-8 /$ min & $R R-4 /$ min & RR no change & $R R+4 /$ min & $R R+8 /$ min \\
\hline 7.30 & 7.35 & 0.27 & 0.38 & 0.53 & 0.74 & 1.03 \\
& 7.30 & 0.51 & 0.72 & 1.00 & 1.40 & 1.95 \\
& 7.25 & 1.05 & 1.46 & 2.04 & 2.85 & 3.97 \\
7.25 & 7.35 & 0.13 & 0.19 & 0.26 & 0.36 & 0.51 \\
& 7.30 & 0.25 & 0.35 & 0.49 & 0.68 & 0.96 \\
& 7.25 & 0.51 & 0.72 & 1.00 & 1.40 & 1.95 \\
\hline
\end{tabular}

$\mathrm{RR}=$ respiratory rate. 
survival rates of $62 \%$ and $58 \%$, respectively, despite the fact that the study design was biased against such a finding. The control element of the study was lost at the point of discharge. No control was maintained over outpatient care or the management of future exacerbations. The latter is important as some patients would have received NIV in subsequent exacerbations and others-for example, in centres where NIV was only available in trial-would not have received NIV due to prior enrolment. Hence, the comparison of long term survival was biased against showing a survival advantage.

Three other controlled but not randomised trials $^{17-19}$ assessing the long term survival of patients with COPD treated with NIV have reported similar findings with 1 year survival rates of $64 \%$ (95\% CI 49 to $79, \mathrm{n}=39),{ }^{18} 71 \%$ $(95 \%$ CI 53 to $89, \mathrm{n}=24),{ }^{17}$ and $87 \%(95 \% \mathrm{CI}$ 69 to $100, n=15) .{ }^{19}$ The equivalent survival rates in the standard treatment groups were less at $30 \%(95 \%$ CI 12 to $47, \mathrm{n}=27),{ }^{18} 50 \%$ (95\% CI 30 to $70, \mathrm{n}=24),{ }^{17}$ and $53 \%$ (95\% CI 28 to $79, \mathrm{n}=15) .{ }^{19}$ However, the survival advantage in our study and that of Confalonieri et $a l^{17}$ appeared to be related to the reduction in in-hospital mortality during the index admission rather than a long term protective effect as the decline in survival after 3 months was identical in the two groups.

The data therefore suggest that the benefit of NIV is in improving survival during the exacerbation itself, and that those in whom in-hospital death was avoided do not represent a high risk group. If they had a very poor prognosis, the survival curves would have converged as these patients died early in the follow up period. Moreover, the median survival of 15.9 months is not sufficiently poor to render NIV inappropriate, at least in terms of survival.

FACTORS ASSOCIATED WITH THE FAILURE OF TREATMENT

On admission patients with the worst degree of acidosis and the highest level of $\mathrm{PaCO}_{2}$ were the most likely to meet criteria for intubation (table 3). Of these two variables, acidosis was the most important clinically. The risk of needing intubation was reduced by NIV. After 4 hours improvements in respiratory rate and in acidosis were associated with success (table 5), but had to be interpreted in the light of the initial $\mathrm{pH}$ and $\mathrm{PaCO}_{2}$. However, at neither enrolment nor in the first 4 hours was it possible accurately to predict on an individual basis who will or will not meet the criteria for intubation. However, these variables can be used as a clinical guide.

The findings of this study are consistent with previously published studies. A low $\mathrm{pH}$ has been shown to be associated with increased mortality $^{20}{ }^{21}$ and the need for intubation ${ }^{22}$ in cohorts of patients admitted to hospital with COPD. Moreover, in controlled and uncontrolled trials of NIV a low initial $\mathrm{pH}^{323}$ and a high $\mathrm{PaCO}_{2}{ }^{32324}$ have been associated with a poor outcome. A fall in $\mathrm{PaCO}_{2}{ }^{23}{ }^{24}$ and improvement in $\mathrm{pH}^{4}{ }^{23-25}$ have also been shown to be protective.
A change in respiratory rate has not previously been reported as a prognostic factor. The fall in respiratory rate is probably explained by an increase in tidal volume which allows the respiratory rate to fall, thus protecting against fatigue but allowing minute ventilation to be maintained. The improvement in tidal volume may occur due to medical treatment and/or NIV. The absence of "allocation to NIV" as a prognostic variable at 4 hours is initially a little surprising. However, NIV has been shown in randomised controlled trials to improve acidosis and reduce respiratory rate. ${ }^{147}$ These variables therefore reflect not only allocation to NIV, but also response to NIV and, as such, the NIV variable is lost from the logistic regression analysis.

It is also valuable to consider variables that were not significant in the analysis, notably hypoxia and radiographic consolidation. Hypoxia on admission in acute exacerbations has not been shown to be associated with mortality or the need for intubation and, as such, the findings in this study are not surprising. ${ }^{3}{ }^{420-25}$ Radiographic consolidation has been shown to be a poor prognostic factor. ${ }^{18} 2326$ However, Rieves et $a l^{26}$ also studied 19 patients with less severe disease and could not find an association with consolidation. They suggested an interplay between disease severity and consolidation. All three studies included patients who were more seriously ill than those in our study. The explanation suggested by Rieves $e a^{26}$ may explain the lack of association in our study finding. Alternatively, these studies were small $(\mathrm{n}=59,33$, and 57, respectively) and the finding may be a statistical anomaly which does not appear in our larger study $(n=236)$.

The lack of discrimination in the prognostic models reflects the methodology used. This was a post hoc analysis and potentially important variables were therefore not considered. For example, Ambrosino et $a^{23}$ found that a low body mass index, a high Apache II score, tachycardia, decreased consciousness, and poor compliance with NIV were associated with failure. These factors were not included in the above analyses because they were not available or, in the case of consciousness, those with a low consciousness were excluded from the trial. The lack of these factors may explain the failure of the models to discriminate in a clinically useful fashion. Notably, health status and lung function before admission were not included. However, in the clinical situation this information is often unavailable within the first 4 hours of an admission.

In conclusion, the initial $\mathrm{pH}$ and $\mathrm{PaCO}_{2}$ can be used clinically to stratify patients according to their risk of meeting criteria for intubation. NIV reduces this risk and, once started, the effectiveness of NIV should be monitored using respiratory rate and improvement in acidosis. Changes in $\mathrm{PaCO}_{2}$ and $\mathrm{PaO}_{2}$ are not associated with either a positive or an adverse outcome and should not be the focus of monitoring. Unfortunately, these variables are not sufficiently predictive to be able accurately to discriminate individuals who will fail and require invasive mechanical ventilation despite 
NIV. Further research is required to develop a predictive model as well as to clarify the importance of radiographic consolidation and of a fall in respiratory rate. With regard to long term survival, NIV appears to be associated with a long term survival advantage but this is achieved by avoiding death during the index admission. Those in whom death is avoided seem to have a similar long term prognosis to the whole group, and the median survival is sufficiently good to support the use of NIV in acute exacerbations of COPD.

1 Brochard L, Mancebo J, Wysocki M, et al. Noninvasive ventilation for acute exacerbations of chronic obstructive pulmonay disease. N Engl f Med 1995;333:817-22.

2 Kramer N, Meyer TJ, Meharg J, et al. Randomized, prospective trial of noninvasive positive pressure ventilation in acute respiratory

3 Bott J, Carroll MP, Conway JH, et al. Randomised controlled trial of nasal ventilation in acute ventilatory failure due to chronic obstructive airways disease. Lancet 1993;341: $1555-7$.

4 Celikel T, Sungur M, Ceyhan B, et al. Comparison of noninvasive positive pressure ventilation with standard medical therapy in hypercapnic acute respiratory failure. Chest 1998;114:1636-42.

5 Angus RM, Ahmed AA, Fenwick LJ, et al. Comparison of the acute effects on gas exchange of nasal ventilation and doxapram in exacerbations of chronic obstructive pulmonary disease. Thorax 1996;51:1048-50.

6 Martin TJ, Hovis JD, Costantino JP, et al. A randomised prospective evaluation of noninvasive ventilation for acute respiratory failure. Am $\mathcal{F}$ Respir Crit Care Med 2000;161: 807-13.

7 Plant PK, Owen JL, Elliott MW. Early use of non-invasive ventilation for acute exacerbations of chronic obstructive pulmonary disease on general respiratory wards: a pulmonary disease on general respiratory wards: a multicen

8 Wood KA, Lewis L, Von Harz B, et al. The use of noninvasive positive pressure ventilation in the emergency department. Chest 1998;113:1339-46.

9 Martin TR, Lewis SW, Albert RK. The prognosis of patients with chronic obstructive pulmonary disease after hospitalization for acute respiratory failure. Chest 1982;82:310-4.

10 Gottleib LS, Balchun OJ. Course of chronic obstructive pulmonary disease following first onset of respiratory failure. Chest 1973;63:5-8.

11 Connors AF, Dawson NV, Thomas C. Outcomes following acute exacerbations of severe chronic obstructive pulmonary disease. Am f Respir Crit Care Med 1996;154:959-67.
12 Gillespie DJ, Marsh HMM, Divertie MB. Clinical outcome of respiratory failure in patients requiring prolonged (greater than 24 hours) mechanical ventilation. Chest 1986; 90:364-9.

13 Kaelin RM, Assimacopoulos A, Chevrolet JC. Failure to predict six-month survival of patients with COPD requiring mechanical ventilation by analysis of simple indices: a prospective study. Chest 1987;92:971-8.

14 Menzies R, Gibbons W, Goldberg P. Determinants of weaning and survival among patients with COPD who require mechanical ventilation for acute respiratory failure. Chest 1989;95:398-405.

15 Gracey DR, Naessens JM, Krishan I, et al. Hospital and posthospital survival among patients with COPD who require mechanical ventilation for acute respiratory failure. Chest 1989;101:211-4.

16 Stauffer JL, Fayter N, Graves B, et al. Survival following mechanical ventilation for acute respiratory failure in adult men. Chest 1993;104:1222-9.

17 Confalonieri M, Parigi P, Scartabellati A, et al. Noninvasive mechanical ventilation improves the immediate and long-term outcome of COPD patients with acute respiratory failure. Eur Respir f 1996;9:422-30.

18 Vitacca $M$, Clini $E$, Rubini $F$, et al. Non-invasive mechanical ventilation in severe chronic obstructive lung disease and acute respiratory failure: short- and long-term prognosis. Intensive Care Med 1996;22:94-100.

19 Bardi G, Pierotello R, Desideri M, et al. Nasal ventilation in COPD exacerbations: early and late results of a prospective, controlled study. Eur Respir f 2000;15:98-104.

20 Jeffrey AA, Warren PM, Flenley DC. Acute hypercapnic respiratory failure in patients with chronic obstructive lung disease: risk factors and use of guidelines for management. Thorax 1992;47:34-40.

21 Warren PM, Flenley DC, Millar JS, et al. Respiratory failure revisited: acute exacerbations of chronic bronchitis between 1961-68 and 1970-76. Lancet 1980;i:467-71.

22 Plant PK, Owen JL, Elliott MW. One-year period prevalence study of respiratory acidosis in acute exacerbations of COPD: implications for the provision of non-invasive ventilation and oxygen administration. Thorax 2000;55:550-4.

23 Ambrosino N, Foglio K, Rubini F, et al. Non-invasive mechanical ventilation in acute respiratory failure due to chronic obstructive airways disease: correlates for success. Thorax 1995;50:755-7.

24 Meduri GU, Turner RE, Abou-Shala N, et al. Noninvasive positive pressure ventilation via face mask. First-line intervention in patients with acute hypercapnic and hypoxemic respiratory failure. Chest 1996;109:179-93.

25 Hilbert G, Gruson D, Gbikpi-Benissan G, et al. Sequential use of noninvasive pressure support ventilation for acute exacerbations of COPD. Intensive Care Med 1997;23:95561

26 Rieves RD, Bass D, Carter RR, et al. Severe COPD and acute respiratory failure. Correlates for survival at the time of tracheal intubation. Chest 1993;104:854-60. 